\title{
INVESTIGATION OF ABRASIVE WATERJET CUTTING OPTIONS FOR MAKING THERMOMECHANICAL TEST SAMPLES
}

\author{
Stepan Jenicek, Vratislav Kotesovec, Michal Pekovic \& Ivana Zetkova
}
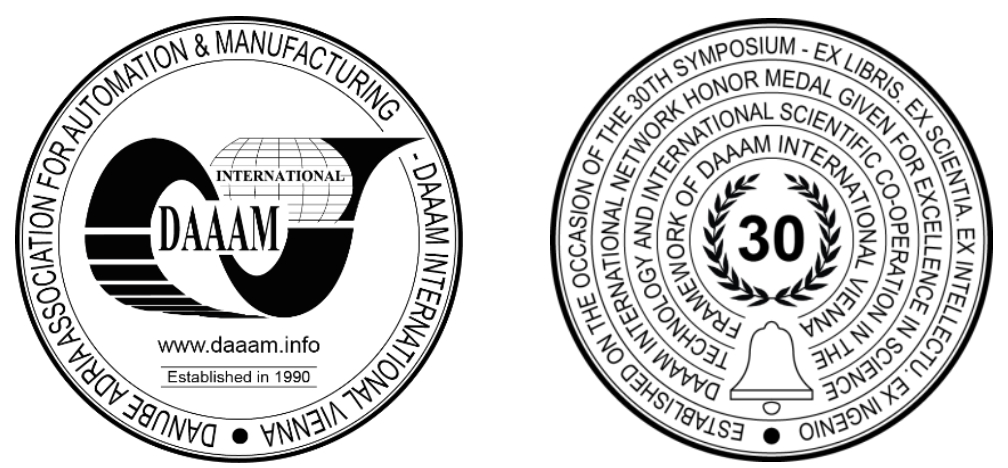

This Publication has to be referred as: Jenicek, S[tepan]; Kotesovec, V[ratislav]; Pekovic, M[ichal] \& Zetkova, I[vana] (2019). Investigation of Abrasive Waterjet Cutting Options for Making Thermomechanical Test Samples, Proceedings of the 30th DAAAM International Symposium, pp.0254-0260, B. Katalinic (Ed.), Published by DAAAM International, ISBN 978-3-902734-22-8, ISSN 1726-9679, Vienna, Austria

DOI: $10.2507 / 30$ th.daaam.proceedings.033

\begin{abstract}
This study examines the options available in the unconventional process of abrasive waterjet cutting for making thermomechanical test samples. A series of experiments was carried out to identify the impact of individual cutting parameters on machined surface integrity. When using abrasive waterjet cutting, most engineering companies only adjust the jet pressure, the stand-off distance, the feed rate and, to a limited extent, the type and amount of abrasive in order to meet customer requirements and the requirements of the workpiece material. Special technologies entitled ProgressJet, MFC (Material Feed Control) and DRC (Dynamic Radius Correction) were experimentally tested in this study. Cutting time without traversing, the average cutting speed, abrasive consumption and the roughness and topography of specimen surfaces were measured. This study of integrity of surfaces produced by abrasive waterjet cutting (AWJ) contributes to evaluation of performance of individual cutting optimization technologies.
\end{abstract}

Keywords: unconventional technologies; abrasive waterjet cutting; AWJ; surface integrity

\section{Introduction}

In order to make high-quality test bars from high-strength metal sheet, a new procedure that could deliver the desired quality and effectiveness had to be developed and put in place. Materials of this kind are characterized by high hardness, strength, and toughness. For this reason, making specimens of these materials by classical chip cutting is difficult and costly. Therefore, it was necessary to design and test a new production process and its effect on the resulting surface integrity.

Generally, an appropriate cutting process must be chosen for each application. There are four primary options: oxyfuel cutting, laser cutting, waterjet technologies and plasma-arc cutting [10]. In this particular case, the purpose was to make specimens for thermomechanical testing. This requirement dictates the quality specifications for samples. The samples were to be used for making optimized test specimens (Fig. 1) for thermomechanical treatment [8], [11], [13] in a thermomechanical simulator [7], [14]. The crucial part of such specimens is the central region (its width and length are $8.2 \mathrm{~mm}$ and $11 \mathrm{~mm}$, respectively). This is where the thermomechanical treatment is actually applied. These specimens are made of sheet metal stock of 6-14 mm thickness. No slag is permissible on the bottom side. 
During production, specimens for thermomechanical treatment must not be affected by heat because their properties are also measured at room temperature. This is the reason why all high-temperature cutting processes [2],[9] were ruled out, i.e. those which impose severe heat effects on the cut area. According to literature [1],[4],[5],[6], abrasive waterjet cutting appears to be the best method. All other methods involve heat effects.

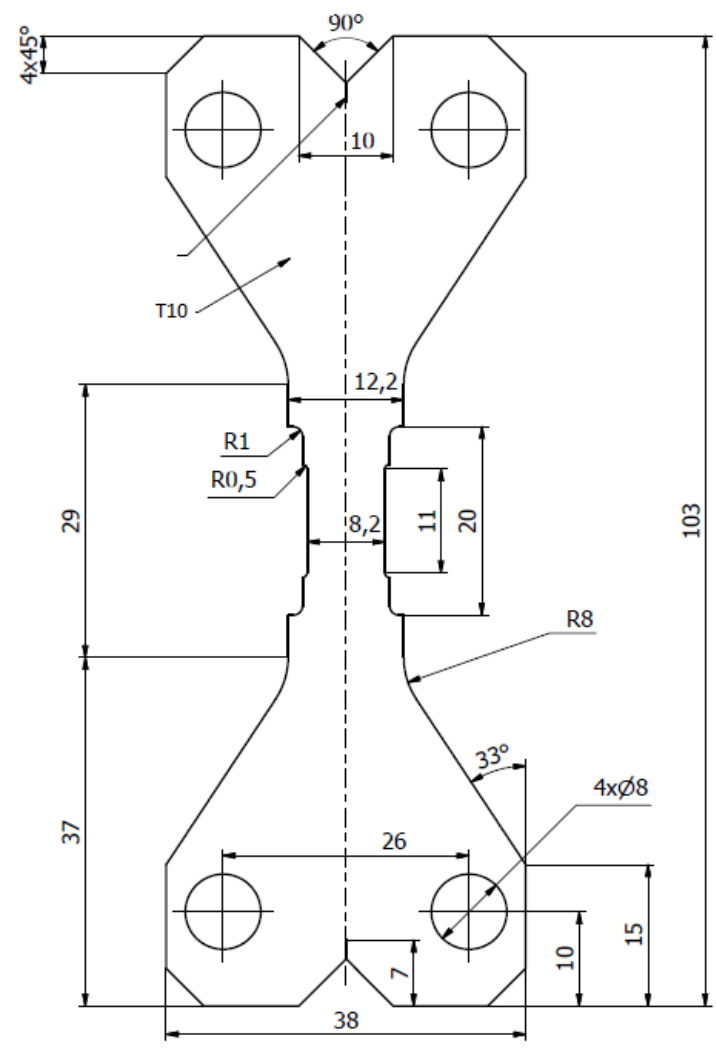

Fig. 1. Specimen drawing

Abrasive waterjet is suitable for cutting all metals, glass, stones, composite material and others. The workpieces may range from a very small thickness to $300 \mathrm{~mm}$ (or more in some cases). Cuts of the highest precision can be made with the aid of a taper compensation function in materials of up to approximately 50 (100) mm thickness. Rough cuts, however, can be made in materials much thicker than $100 \mathrm{~mm}$ [3]. The process performs well with steels of reasonable thickness and produces smooth and extremely precise cuts. In terms of precision, abrasive waterjet cutting can even outperform laser cutting, as it produces smoother edges free from thermal distortion. Waterjet cutting is not limited by thickness, unlike laser or plasma technologies. One disadvantage of waterjet cutting, however, is high costs. The costs of the machine are higher those of plasma equipment (due to an expensive high-pressure pump) but lower than those of laser equipment. The operating costs of waterjet cutting are much higher than those of laser cutting, mainly due to the price of abrasive $[1]$.

\section{Cutting optimization technologies}

Tests were carried out using the WJ2830-2Z-Cobra-PJ60 machine from the company PTV, spol. s r.o. This manufacturer has developed and implemented technologies for higher speed, better precision and lower production costs, entitled ProgressJet, MFC (Material Feed Control) and DRC (Dynamic Radius Correction). The purpose of these experiments was to assess the performance of these technologies with respect to cut surface quality and dimensional accuracy.

\subsection{ProgressJet}

This technology's mechanical system can eliminate process related errors on the cut surface caused by the abrasive jet stream and by its physical effects. It compensates for taper (draft angle) - i.e. the offset of the bottom edge with respect to the top edge. With ordinary workpiece materials (structural steel, stainless steel, aluminium alloys, titanium, brass, copper) the ProgressJet function can successfully compensate for a draft angle of $+/-0,05 \mathrm{~mm}$ (in thicknesses under 50 $\mathrm{mm})$. With other materials, the basic set-up of ProgressJet may not eliminate the taper correctly. If the taper correction fails in any material, the set value should be adjusted in the "Custom Settings" dialogue box. [12] 


\subsection{Material Feed Control-MFC}

This function compensates for the cutting speed increase or decrease in order to prevent kickback, taper, striation marks and other effects. This algorithm is still under development but it performs relatively well already. Essentially, the movement speed ramps up until the width of the jet stream at the top and bottom equalizes. The resultant speed is maintained along a tool path - which is related to the workpiece thickness - and then slowly increases. As the jet stream approaches a curve or the tool path end, its movement slows down along the same ramp, after which the reduced speed is maintained until the jet stream tail catches up. The speed settings for cutting individual features are based on the predicted behaviour of the jet stream tail which lags behind the jet stream entry point. The objective is to keep the deviation of the jet stream from the cutting path within specified limits. [12]

\subsection{Dynamic Radius Correction - DRC}

This is another compensation method intended to improve the cut quality. During cutting, the jet stream tail becomes narrower and lags behind the entry point and even the top kerf width changes. The system attempts to compensate for this kerf width change based on earlier tests. The jet stream diameter correction is set by the user on the basis of a test cut in which the "maximum diameter" is determined. During cutting, the system subtracts the estimated diameter change from this maximum value. This function is now implemented in a trial mode and it will continue to be upgraded. Current results show that it is more effective in thinner materials in which the difference between the widest and narrowest kerf is largest [12].

\section{Experiments}

A series of experiments was carried out to identify the impact of individual cutting parameters on surface integrity. When using abrasive waterjet cutting, most engineering companies only adjust the jet pressure, the stand-off distance, the feed rate and, to a limited extent, the type and amount of abrasive in order to meet customer requirements and the requirements of the workpiece material. For these reasons, special technologies for cutting optimization (as described in section 2) were tested experimentally. A comparison was made with a specimen which had been cut using a micro nozzle with a finer abrasive (specimen no. 7). The impact of a $50 \%$ reduction of the Q5 quality-based feed rate was studied as well (specimen no. 6).

The cutting parameters were varied, as shown in Table 1. The arrangement for all specimens was as follows:

\begin{tabular}{|c|c|c|c|c|}
\hline $\begin{array}{c}\text { Specimen } \\
\text { number }\end{array}$ & $\begin{array}{c}\text { Quality-based } \\
\text { feed }\end{array}$ & ProgressJet & MFC & DRC \\
\hline 1 & Q5 & X & & \\
\hline 2 & Q5 & & $X$ & \\
\hline 3 & Q5 & & & $X$ \\
\hline 4 & Q5 & X & X & X \\
\hline 5 & Q5 & & & \\
\hline 6 & $\begin{array}{c}\text { half of Q5 set } \\
\text { value }\end{array}$ & & & \\
\hline 7 & $\begin{array}{c}\text { Q5 with mesh } \\
\text { 200 abrasive }\end{array}$ & & & \\
\hline 8 & Q5 & & $X$ & $X$ \\
\hline
\end{tabular}

Table 1. Experimental cutting set-up

Test arrangement:

- $\quad$ PTV JETS 3.8/60-COMPACT high pressure pump (max. operating pressure $415 \mathrm{MPa}$, max. flow 3.8 1/min)

- $\quad$ X-Y cutting table PTV WJ2830-2Z (working space of $3000 \times 2000 \mathrm{~mm}$ )

- Continuously variable cutting speed 0-20 m/min

Experimental conditions:

- Operating pressure [MPa]: 415

- Abrasive type: Indian garnet

- Abrasive particle size [mesh size]: 80, except for specimen 7, where it was 200

- Mass flow of abrasive - [g/min]: 300, except for specimen 7, where it was 50

- Water nozzle diameter: $0.33 \mathrm{~mm}$, except for specimen 7 , where it was 0.1 
- Abrasive nozzle diameter: $0.91 \mathrm{~mm}$, except for specimen 7, where it was 0.50

- Stand-off distance (between the jewel and the workpiece) [mm]: 4

Workpiece material:

- S235JR

- Thickness [mm]: 10

No generally applicable standards for evaluating the topography of surfaces made by AWJ cutting have been developed or implemented yet. Nevertheless, a classification scale for cut surface quality has been around of quite a few years. Its range is from Q1, the poorest quality, to Q5, the best surface finish. Although the users of AWJ generally follow this classification, there are differences between their assigned grades. The main reason is that this classification scale lacks definitions of surface accuracy and quality for its individual grades.

\subsection{Measured values}

Surfaces created by AWJ differ in qualitative terms from those produced by conventional methods. Their topography is rougher and more ragged. Their quality usually decreases with the distance from the point where the jet stream enters the workpiece. Some deficiencies are visible to the naked eye (burrs, striations) but others must be identified using special instruments (unfavourable roughness, dimensional accuracy and perpendicularity). As the requirements for the cut quality differ from product to product, defects should be assessed on a case-by-case basis. The function and the quality of the part, however, must be ensured.

The characteristics under investigation included the cutting time without traversing, the average cutting speed, abrasive consumption and the roughness and topography of the cut surface. Roughness was measured near the top edge and near the bottom edge, in each case on three cross sections. Surface roughness and topography were evaluated using the IFM G4 scanning optical microscope. The readings are listed in Table 2. For the sake of clarity, the data were averaged and only suitable type representatives were chosen. They are plotted as percent values in Graph 1 where the poorest result is represented as $100 \%$.

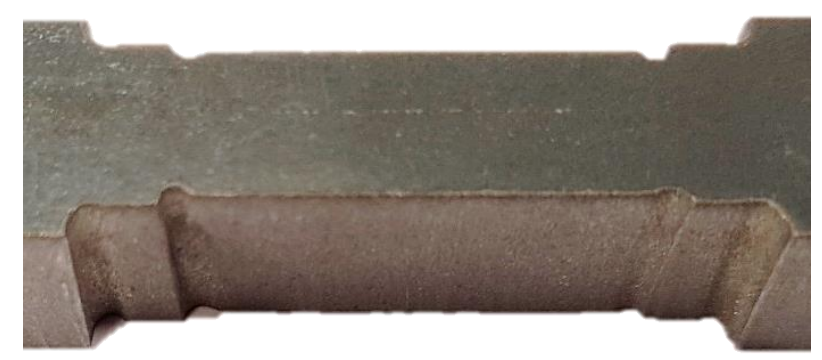

Fig. 2. Detail of cut specimen 1(ProgressJet)

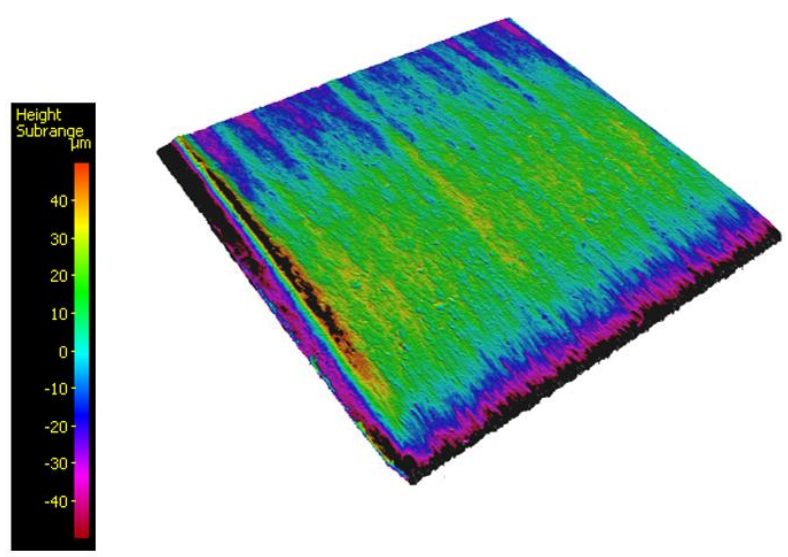

Fig. 3. Topography of cut specimen 1(ProgressJet) 


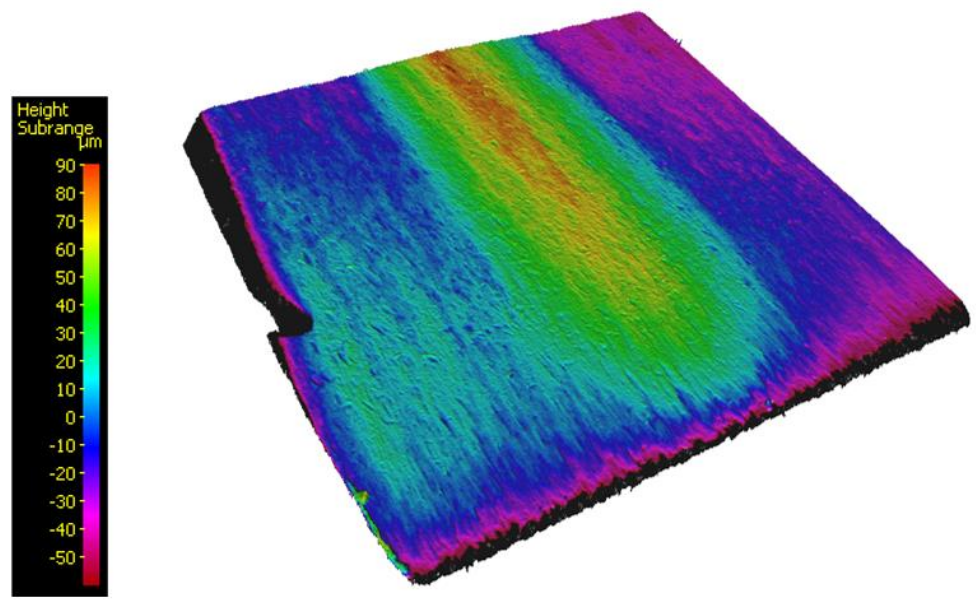

Fig. 4. Topography of cut specimen 2(MFC)

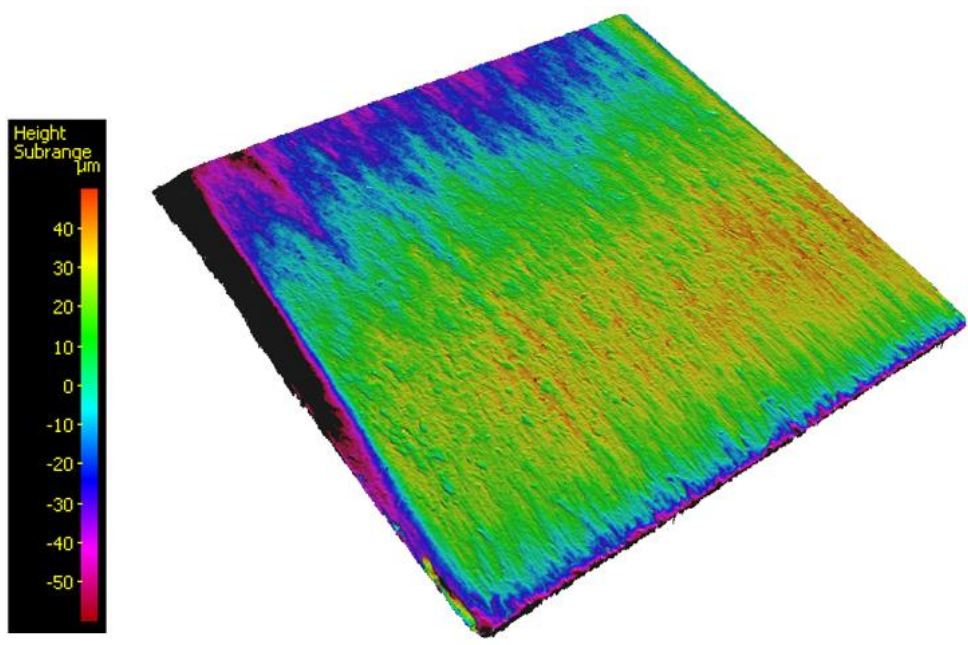

Fig. 5. Topography of cut specimen 5(no optimization technology)

\begin{tabular}{|c|c|c|c|c|c|c|c|c|c|c|}
\hline \multicolumn{2}{|c|}{ Specimen number } & & 1 & 2 & 3 & 4 & 5 & 6 & 7 & 8 \\
\hline \multicolumn{2}{|c|}{ Cutting time } & {$[s]$} & 108 & 243 & 107 & 170 & 107 & 206 & 898 & 243 \\
\hline \multicolumn{2}{|c|}{ Average cutting speed } & $\mathrm{mm} / \mathrm{min}$ & 87 & 41 & 88 & 57 & 88 & 48 & 11 & 41 \\
\hline \multicolumn{2}{|c|}{ Abrasive consumption } & {$[\mathrm{g}]$} & 546 & 1220 & 541 & 859 & 541 & 1039 & 738 & 1220 \\
\hline \multirow{12}{*}{ 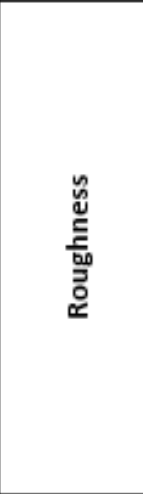 } & \multirow{6}{*}{ Top edge } & $\operatorname{Ra}[\mu \mathrm{m}]$ & 5.8 & 6.4 & 5.9 & 6.4 & 5.1 & 5.6 & 3.1 & 5.9 \\
\hline & & $\sigma \mathrm{Ra}[\mu \mathrm{m}]$ & 0.1 & 0.6 & 0.4 & 0.5 & 0.1 & 0.6 & 0.2 & 0.5 \\
\hline & & Rt $[\mu \mathrm{m}]$ & 53.1 & 60.1 & 116.0 & 57.6 & 48.2 & 49.1 & 31.2 & 51.7 \\
\hline & & $\sigma \mathrm{Rt}[\mu \mathrm{m}]$ & 9.9 & 10.0 & 59.0 & 6.5 & 1.4 & 10.9 & 4.9 & 8.6 \\
\hline & & $\mathrm{Rz}[\mu \mathrm{m}]$ & 39.9 & 43.0 & 56.9 & 43.8 & 39.2 & 40.5 & 23.6 & 40.2 \\
\hline & & $\sigma \mathrm{Rz}[\mu \mathrm{m}]$ & 2.4 & 1.4 & 10.8 & 1.3 & 6.4 & 6.5 & 7.6 & 2.0 \\
\hline & \multirow{6}{*}{ Bottom edge } & $\operatorname{Ra}[\mu \mathrm{m}]$ & 6.9 & 9.0 & 7.1 & 9.5 & 10.5 & 5.6 & 3.1 & 10.3 \\
\hline & & $\sigma \mathrm{Ra}[\mu \mathrm{m}]$ & 0.3 & 0.2 & 0.4 & 0.2 & 0.2 & 0.4 & 0.1 & 0.6 \\
\hline & & Rt $[\mu \mathrm{m}]$ & 49.4 & 71.4 & 55.5 & 78.6 & 81.3 & 57.0 & 25.2 & 91.9 \\
\hline & & $\sigma \mathrm{Rt}[\mu \mathrm{m}]$ & 2.5 & 4.6 & 3.7 & 5.5 & 4.1 & 11.8 & 0.7 & 3.3 \\
\hline & & $\mathrm{Rz}[\mu \mathrm{m}]$ & 42.0 & 53.0 & 46.0 & 58.5 & 62.0 & 42.2 & 20.4 & 59.9 \\
\hline & & $\sigma \mathrm{Rz}[\mu \mathrm{m}]$ & 1.5 & 11.4 & 2.9 & 5.0 & 7.1 & 3.5 & 2.6 & 14.7 \\
\hline \multirow{3}{*}{ 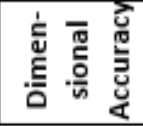 } & Top edge & {$[\mathrm{mm}]$} & 8.196 & 8.193 & 8.002 & 8.118 & 7.923 & 8.097 & 8.144 & 8.018 \\
\hline & Centre & {$[\mathrm{mm}]$} & 8.220 & 8.349 & 8.138 & 8.140 & 8.090 & 8.194 & 8.180 & 8.162 \\
\hline & Bottom edge & {$[\mathrm{mm}]$} & 8.182 & 8.434 & 8.258 & 8.128 & 8.170 & 8.260 & 8.197 & 8.221 \\
\hline
\end{tabular}

Table 2. Measured values 


\section{Measured values}

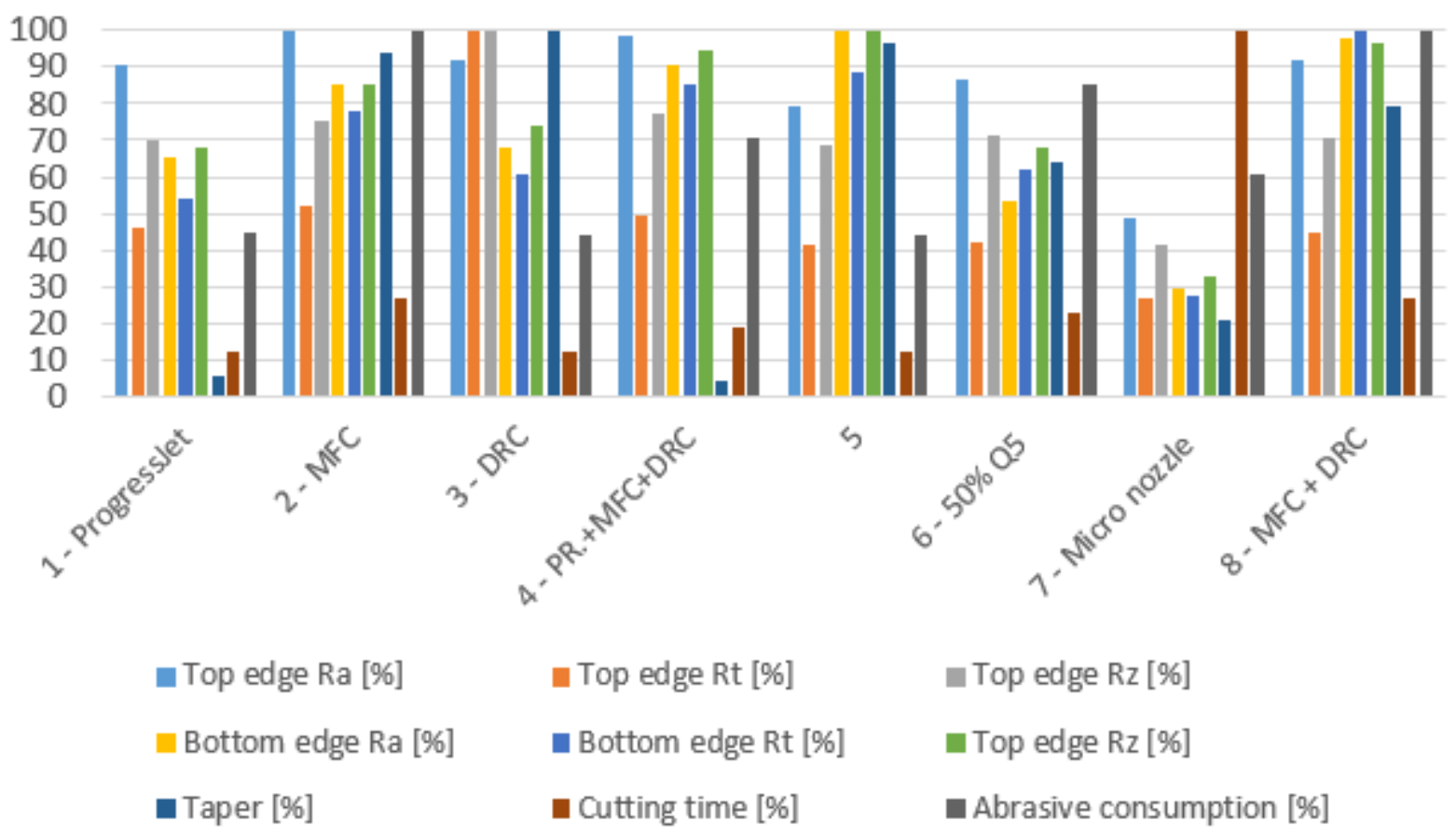

Graph 1. Graphical representation of measured values

The best roughness was obtained with a micro nozzle and fine abrasive (specimen 7): the difference between the width on the top and bottom faces was $0.05 \mathrm{~mm}$. This was an excellent outcome, given that no cutting optimization technology had been employed. The use of the micro nozzle led to the longest cutting time and therefore the highest price. The smallest difference between the width on the top and bottom faces (the smallest taper) was achieved with the ProgressJet technology (specimens 1 and 4): $0.01 \mathrm{~mm}$. An interesting observation is that the centre of the specimen was approximately $0.02 \mathrm{~mm}$ higher. This was confirmed by documenting the surface topography (Fig. 3). Specimen 1 which was made with no other optimization technology but ProgressJet contained a prominent notch of approx. 0.3 mm near the R0.5 radius (see Fig. 1 and Fig. 2) which was probably caused by machine oscillation during dynamic tilting (using factoryset dynamic parameters, which will be varied in further experiments). Such a notch is unacceptable in thermomechanical test specimens. In specimen 4 made with the use of ProgressJet, MFC and DRC, the notch was less prominent (approx. $0.1 \mathrm{~mm}$ ). The width of specimen 2 made with MFC was nonuniform due to this technology, and the variation was approx. $0.13 \mathrm{~mm}$. It is because this technology slows down the feed rate before curves and directional changes (in this case, ahead of R0.5 as shown in Fig. 1) and speeds up again after them. When DRC is activated together with MFC (specimen 8), this behaviour is eliminated. The effects of this behaviour on surface topography are shown in Fig. 4. Specimen 5 (Fig. 5 ), which was made with Q5 quality-based feed rate and without any cutting optimization technologies, exhibited one of the largest taper values $(0.247 \mathrm{~mm})$. Specimen 6 , which was made without any cutting optimization technologies and with the use of only $50 \%$ feed rate of the Q5 setting, exhibited $34 \%$ less taper than specimen 5 which was also made without any cutting optimization technologies. The use of DRC (specimen 3) does not substantially change the cutting time, surface quality or taper, when compared to cutting without cutting optimization technologies.

From engineering and economic viewpoints, the production of specimens for thermomechanical testing is best performed without cutting optimization technologies because the taper on specimen surfaces is to no detriment here.

\section{Conclusion}

Because many paths lead to a goal, each product can be manufactured in different ways. In the production of test samples from high-strength sheets, the aim was to produce the product in a manner that fulfills not only all the essentials of the drawing documentation, but will also be produced by the cheapest and fastest process. Another aim was to determine the influence of individual cutting parameters on the resulting surface integrity, resulting cutting time and the amount of abrasive consumed.

The surfaces created by AWJ machining have a specific texture (see Figs. 2 to 5). Their topography is rougher and more ragged. Their quality usually decreases with the distance from the point where the jet stream enters the workpiece. This study of integrity of surfaces produced by abrasive waterjet cutting (AWJ) contributes to performance evaluation of individual cutting optimization technologies. The smallest difference between the width on the top and bottom faces (smallest taper) was achieved with the ProgressJet technology (specimens 1 and 4), where the difference was $0.01 \mathrm{~mm}$. 
Specimen 1, which was made with the ProgressJet technology, contains a prominent notch of approx. $0.3 \mathrm{~mm}$ near R0.5 radius (Figs. 1 and 2) which was most probably caused by the ProgressJet technology itself. Such a notch is unacceptable in thermomechanical test specimens. In specimen 4 made with ProgressJet, MFC and DRC technologies, the notch was less prominent (approx. $0.1 \mathrm{~mm}$ ). From engineering and economic viewpoints, the production of specimens for thermomechanical testing is best performed without cutting optimization technologies because the taper on specimen surfaces is to no detriment here.

In the future, we will focus on optimizing the technological cutting conditions, especially the influence of the type of abrasive, the amount of abrasive material, and their effect on surface integrity.

\section{Acknowledgments}

The present contribution has been prepared with the support of the student grant competition of University of West Bohemia in Pilsen, SGS 2019-019 Material-technological research of advanced high strength steels. The project is subsidised from specific resources of the state budget for research and development.

\section{References}

[1] http://www.esabna.com/us/en/education/blog/what-is-the-best-way-to-cut-steel-plate.cfm, (2013). What Is The Best Way To Cut Steel Plate, ESAB Knowledge Center, Accessed on: 2018-08-11

[2] Kašpar J. (2011). Thermal oxidative cutting, Tepelné dělení materiálu kyslíkem, MM Průmyslové spectrum, Vol. 2011, No. 24, pp 25, ISSN: 1212-2572

[3] http://www.flowwaterjet.com/Resources/Ask-Dr-Hashish-a-Question, (2018). Ask Dr. Hashish - Dr. Mohamed Hashish is the inventor of the abrasive waterjet and an expert in high pressure design and tribology., Accessed: 2018$02-5$

[4] Humar, A. (2005). Machining technology - 3th part. Interactive multimedia script for bachelor and master study programme.Technologie obrábění - 3. část. Interaktivní multimediální text pro bakalářský a magisterský studijní program. Brno: Brno University of Technology. Faculty of Mechanical Engineering, 2009.

[5] Wang, J. (2003). Abrasive waterjet machining of engineering materials, Trans Tech Publications, Switzerland, ISBN 0-87849-918-0.

[6] Dvorak, J. (2009). Surface integrity of materials cut by progressive technologis, Integrita rozhraní materiálů obráběných progresivními technologiemi. Brno: Brno University of Technology. Faculty of Mechanical Engineering, 2009.

[7] Jenicek, S.; Vorel, I.; Kana, J. \& Opatova, K. (2017). The Use of Material-Technological Modelling to Determine the Effect of Temperature and Amount of Deformation on Microstructure Evolution in a Closed-Die Forging Treated by Controlled Cooling, Manufacturing Technology, Vol. 17, No.3, pp. 32,6-330

[8] Vorel, I.; Jenicek, S.; Kana, J.; Ibrahim, K. \& Kotesovec, V. (2016). Use of Optical and Electron Microscopy in Evaluating Optimization by Material-Technological Modelling of Manufacturing Processes Involving Cooling of Forgings. In: Manufacturing Technology, Vol. 16, No. 6, pp. 1383-1387.

[9] Roubíček, M. (2016). Criteria for the choice of method and trends in materials thermal cutting. Kriteria volby metody a trendy tepelného dělení materiálu, Available http://www.airliquide.cz/file/otherelement/pj/roubicek49122.pdf, Accessed: 2018-09-10

[10] Jenicek, S; Kotesovec, V; Kalina, T \& Masek, B (2016). Use of Waterjet in Manufacturing Test Bars of HighStrength Steels, Proceedings of the 27th DAAAM International Symposium, pp.0219-0224, B. Katalinic (Ed.), Published by DAAAM International, ISBN 978-3-902734- 08-2, ISSN 1726-9679, Vienna, Austria

[11] Jemicek, S.; Vorel, I. \& Kana, J. (2018). Metallographic Observation for Evaluating Microstructural Evolution on Various Cross-Sections of Forged Part upon Air-Cooling from Finishing Temperature. In: Manufacturing Technology, Vol. 18, No. 1, pp. 53-56

[12] PTV (2016). User manuals for the machine PTV JETS 3.8/60-COMPACT, PTV, spol. s r.o

[13] Bublikova, D.; Jenicek S.; Vorel, I. \& Masek, B. New heat treatment process for advanced high-strength steels. In IOP Conference Series-Materials Science and Engineering. Bristol: IOP PUBLISHING LTD, 2017. s. 1-8. ISBN: neuvedeno, ISSN: 1757-8981

[14] Jenicek, S.; Vorel, I.; Kana, J; Opatova, K.; Rubesova, K.; Kotesovec, V. \& Masek, B. Evolution of microstructure and mechanical properties during Q\&P processing of medium-carbon steels with different silicon levels. In IOP Conference Series-Materials Science and Engineering. Bristol: IOP PUBLISHING LTD, 2017. s. 1-6. ISBN: neuvedeno, ISSN: 1757-8981 